the after-treatment, as at the first dressing, the pupil reacted promptly to light. The filtration is very marked, and the tension is still somewhat subnormal.

The fourth patient, operated on March 11 last, also had normal tension and good filtration.

In concluding, I hope I have rendered easier the operation for simple glaucoma, and as far as I am concerned, I can assure you that facing sufferers from this disease, who usually come to me when they have already lost the sight of one eye, and with a contracted field in the other eye, I feel much easier, and I suggest operation more willingly to these unfortunate sufferers, who without the proper.treatment, would ultimately become totally blind.

\title{
PARALYSIS OF DIVERGENCE IN ENCEPHALITIS LETHARGICA
}

\author{
BY \\ E. R. Chambers \\ BRISTOL
}

THE following case is, I think, worthy of note, as it illustrates an uncommon type of diplopia occurring in the recent epidemic of encephalitis lethargica.

Girl, age 19. Complained of diplopia. Two evenings before seeing me, she had had headache and giddiness and felt sick; on the following morning she awoke with diplopia. The diplopia was very troublesome when looking at distant objects, but was hardly present at all in near vision. There was no drowsiness. Temperature $101^{\circ}$. She had not had influenza nor any other recent illness. Examination of eyes showed no ptosis, no manifest squint, pupils were normal in size, equal, and reacted to light and accommodation. Both optic discs and fundi were normal. The movements of both eyes were normal.

An examination of the diplopia in the six cardinal directions of gaze showed it to be homonymous, with erect images, the unusual feature being that there was no alteration in the relative position of the two images in any of the six cardinal directions of gaze. The first examination was carried out with the candle at three metres from the patient. A second examination, carried out at five metres, showed the two images to be further apart than they were when the examination was performed at three metres from the patient, but, again, their relative positions remained the same in the six cardinal directions of gaze. On approximating the 
candle to two feet from the patient, the diplopia ceased to exist in all six cardinal directions of gaze.

This case could not have been one of paresis of any individual muscle as there was no increase in the distance between the images in the direction of action of any muscle, nor could spasm of accommodation produce the above type of diplopia, as in this case the double vision would increase as the object was brought' nearer the patient and diminish the further it was removed.

In the above-mentioned case, the diplopia disappeared in a week from its onset, and the patient made an uneventful recovery, for the time being at any rate. No convergent squint ultimately appeared in this case as has happened with some of the cases under observation.

During the last few weeks I have seen six cases in which the diplopia has been similar to that described above. The condition is quite new to me, but from a perusal of what literature I have at hand these cases would appear to be due to a paralysis of divergence.

Dunnington, in the Arch. of Ophthal., 1923, quotes three cases of paralysis of divergence occurring with encephalitis lethargica, the type of diplopia in his cases being exactly similar to that seen in the cases here. Duane discussing the subject (Arch. of Ophthal., 1899) states that divergence is an active as well as a passive movement, brought about by relaxation of both internal recti, accompanied by contraction of the external recti, and that the nervous mechanism of this movement is controlled by a centre (the centre for divergence) situated in close proximity to the sixth nerve nucleus, thus accounting for the common occurrence of convergent squint with or following a paralysis of divergence.

\section{OXFORD OPHTHALMOLOGICAL CONGRESS}

UNDER the Mastership of Sir Anderson Critchett, Bart., K.C.V.O., the Oxford Ophthalmological Congress held its fifteenth annual meeting at Oxford on July 2, 3, 4 and 5 .

With a membership of 380 the expectation that it would be well attended was realized, for the number closely approached that of last year which stands as a record. The proceedings were held as before, in the Department of Human Anatomy through the kindness of Professor Arthur Thomson, whilst the hospitality of Keble College was again available for board and lodging.

On July 3 the Congress was opened by the Master with an address of welcome in which, after witty allusions to the programme, 
he expressed pleasure at the presence of Dr. E. Landolt, of Paris, and Dr. G. E. de Schweinitz with others from America.

This was followed by a discussion on "The General Principles of the Treatment of Convergent Concomitant Strabismus" (excluding the description of details of operations) the openers being Dr. E. LANDOLT (Paris) and Dr. ERNEST THOMSON (Stirling). Dr. G. E. de Schweinitz (Philadelphia), Dr. T. HARRISON BUtler (Birmingham), Mr. R. BEATSON HiRd (Birmingham), Mr. ERnest Clarke (London), Mr. A. F. MacCallaN, (London), Mr. ClaUd Worth (London), Mr. Angus MacGillivray (Dundee), Dr. Stewart Barkie (Glasgow) and Dr. MARION GILCHRIST (Glasgow) contributed to the discussion.

In the afternoon, demonstrations were given in the Scientific Museum by the following :

Dr. GEORGE Young (Colchester) who described his operation of double sclerectomy by trephining without communication with the anterior chamber and showed a specimen illustrating the success of the procedure.

Dr, RAYNER BATTEN (London) showed with the epidiascope a valuable collection of drawings of fundi from cases of cardio-vascular disease, macular, cerebro-macular and congenital diseases with a number of others unclassified.

$\mathrm{He}$ also demonstrated models of fundus conditions, the hydrophthalmoscope, special rigid spectacles for ptosis with a case showing their value, a fixation fork for the insertion of sutures in advancements and tension experiments with balloons.

Dr. THOMSON HENDERSON (Nottingham) showed a good series of pathological sections including a number to illustrate the evolution of the ciliary muscle in mammalia.

Dr. H. M. TRAQUAIR (Edinburgh) gave a demonstration of his method of perimetry.

Mr. J. H. TomLinson (London) showed (1) Pulfrich's illusion, (2) Independence of colour perception. of the two eyes, (3) Query Summation of brilliance values of the two eyes.

Mr. A. F. MACCALLAN, (London) gave a short account of the treatment of trachoma.

Mr. P. H. ADAMs showed some interesting specimens of secondary carcinoma of the choroid and other conditions.

Dr. HARRISON BUTLER (Birmingham) demonstrated Hess's apparatus for the investigation of Muscle Paresis.

Mr. ARTHuR GREene (Norwich) showed a pair of double scissors for use in lengthening of muscles by partial section.

In the Commercial Museum fourteen firms of ophthalmic instrument makers exhibited models of the newest appliances and apparatus used in ophthalmic work, whilst an exhibit which 
attracted a good deal of attention was that of the manufacture of artificial eyes in which the process could be followed from the beginning to the finished product.

On Friday morning, Dr. Howard F. HANSEll (Philadelphia) opened the session with a paper describing four cases of atypical retinitis pigmentosa associated with developmental abnormalities and occurring in members of one family, and was followed by Professor H. Friedenwald (Baltimore) who dealt, in an interesting contribution, with the relationship between chorioretinitis juxtapapillaris (Jensen's disease), and other forms of chorio-retinitis.

After a short interval, Dr. T. HARRISON BUtLER (Birmingham) delivered the Doyne Memorial Lecture, his subject being "Focal Illumination of the Eye with special reference to the clinical use of the Gullstrand Slit-Lamp." As a pioneer in the subject in this country, the lecturer was closely followed, much interest being shown in the admirable series of original pictures illustrating various pathological conditions as seen with the corneal microscope and the slit-lamp. At the close Dr. Butler was presented by the Master with the Doyne Memorial Medal.

The morning session closed with a short address by Dr. PARK LEWIS on "Preventive Ophthalmology" as an organised movement in which he urged the value of international co-operation in the subject.

The afternoon session was held at the Eye Hospital, where a demonstration of the corneal microscope and Gullstrand Slit-Lamp was held under the direction of Dr. HARRISON BUTLER, assisted by Mr. R. J. Coulter and Mr. B. CRIDland. Four instruments were in use and a good number of patients were available for examination through the help of the Deputy Master, Mr. P. H. Adams.

On Saturday morning, a paper was read by Mr. H. Holmes Joy, K.C., dealing with such legal matters and procedure as might especially concern the medical man in general and the ophthalmic surgeon in particular.

Containing much useful advice to the expert medical witness and the specialist medical referee, the paper was well received and greatly appreciated by a good audience.

In conclusion Mr. Joy raised the question as to whether one attack of coal-miners' nystagmus gave rise to an increased susceptibility to future attacks and stated that it would be of considerable assistance with regard to compensation cases under the Workmen's Compensation Act if some unanimity of opinion could be expressed by the Congress upon the point.

A good discussion followed in which the following took part :Messrs. C. F. HARFord, Arthur GReENe, B. CRIDLAND, Colonel 
A. H. Tubby, Messrs R. J. Coulter, R. Jagues, G. H. Pooley, E. Park-Lewis, A. S. Percival, Angus MacGillivray and LISTER LLEWELLYN.

On the afternoon of Thursday, a garden party had been arranged in the Gardens of University College but owing to the weather the members of the Congress and their friends were received in the Hall of the College. Dr. Ainley Walker, Dean of the Medical Faculty of the University, and Mrs. Walker acted as host and hostess.

The Annual Dinner of the Congress was held on the same day in the Hall of Keble College and was well attended, amongst those present being Sir T. Herbert Warren, The President of Magdalen College, Dr. Ainley Walker, Dr. de Schweinitz, Sir George BerRy, M.P., Dr. Gibson, Dr. Howard F. Hansell, Dr. Park Lewis and Professor Friedenwald.

No meeting of the Congress will take place in 1925 on account of the Convention of English-Speaking Ophthalmological Societies which will be held in London in July of that year.

\section{ANNOTATIONS}

\section{Ocular Palsies in Encephalitis Lethargica}

The diagnosis of the cause of the more obscure cases of ocular palsy is never an easy one. Encephalitis lethargica, especially in its milder forms, is one of the less common causes. Dr. C. W. Yow, in a recent communication to the Lancet, (June 21, 1924), has given an analysis of the cases of diplopia seen at the Royal Eye Hospital, from the beginning of the year to the end of May, amongst which were 21 undoubted cases of encephalitis all with a history of diplopia. There was a marked increase of the number of cases of diplopia in the month of April which is attributed by the author to a coincident increase in the number of cases of encephalitis.

We do not think that there is any risk of this cause of ocular palsy being overlooked by the profession, the tendency is rather the other way. Cases of serious intracranial disease such as cyst of the cerebellum, temporo-sphenoidal tumour, tuberculous meningitis etc., have recently come under our notice wrongly diagnosed as encephalitis lethargica, mainly on account of the presence of oculo-motor paralysis. 